\title{
Optimization of Xylanase Production by Filamentous Fungi in Solid-State Fermentation and Scale-up to Horizontal Tube Bioreactor
}

\author{
N. Pérez-Rodríguez • F. Oliveira • B. Pérez-Bibbins • \\ I. Belo • A. Torrado Agrasar • J. M. Domínguez
}

Received: 14 January 2014 / Accepted: 26 March 2014 /

Published online: 12 April 2014

(C) Springer Science+Business Media New York 2014

\begin{abstract}
Five microorganisms, namely Aspergillus niger CECT 2700, A. niger CECT 2915, A. niger CECT 2088, Aspergillus terreus CECT 2808, and Rhizopus stolonifer CECT 2344, were grown on corncob to produce cell wall polysaccharide-degrading enzymes, mainly xylanases, by solid-state fermentation (SSF). A. niger CECT 2700 produced the highest amount of xylanases of $504 \pm 7 \mathrm{U} / \mathrm{g}$ dry corncob (dcc) after 3 days of fermentation. The optimization of the culture broth $\left(5.0 \mathrm{~g} / \mathrm{L} \mathrm{NaNO}_{3}, 1.3 \mathrm{~g} / \mathrm{L}\left(\mathrm{NH}_{4}\right)_{2} \mathrm{SO}_{4}, 4.5 \mathrm{~g} / \mathrm{L} \mathrm{KH}_{2} \mathrm{PO}_{4}\right.$, and $3 \mathrm{~g} / \mathrm{L}$ yeast extract) and operational conditions ( $5 \mathrm{~g}$ of bed loading, using an initial substrate to moistening medium of 1:3.6 $(w / v)$ ) allowed increasing the predicted maximal xylanase activity up to $2,452.7 \mathrm{U} / \mathrm{g}$ dcc. However, different pretreatments of materials, including destarching, autoclaving, microwave, and alkaline treatments, were detrimental. Finally, the process was successfully established in a laboratory-scale horizontal tube bioreactor, achieving the highest xylanase activity $(2,926 \mathrm{U} / \mathrm{g} \mathrm{dcc})$ at a flow rate of $0.2 \mathrm{~L} / \mathrm{min}$. The result showed an overall 5.8-fold increase in xylanase activity after optimization of culture media, operational conditions, and scale-up.
\end{abstract}

Keywords Corncob $\cdot$ Xylanases $\cdot$ Solid-state fermentation $\cdot$ Aspergillus niger

N. Pérez-Rodríguez $\cdot$ F. Oliveira $\cdot$ B. Pérez-Bibbins $\cdot$ J. M. Domínguez Department of Chemical Engineering, Faculty of Sciences, University of Vigo (Campus Ourense), As Lagoas s/n, 32004 Ourense, Spain

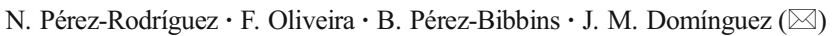
Laboratory of Agro-food Biotechnology, CITI (University of Vigo)-Tecnópole, Parque Tecnológico de Galicia, San Cibrao das Viñas, Ourense, Spain e-mail: jmanuel@uvigo.es

F. Oliveira $\cdot$ I. Belo

Centre of Biological Engineering, University of Minho, Campus de Gualtar, 4710-057 Braga, Portugal

A. Torrado Agrasar

Bromatology Group, Department of Analytical and Food Chemistry, Faculty of Sciences,

University of Vigo (Campus Ourense), As Lagoas s/n, 32004 Ourense, Spain 


\section{Introduction}

Contrary to submerged fermentations ( $\mathrm{SmFs}$ ), solid-state fermentation (SSF) involves the growth and metabolism of microorganisms on moist solids in the absence or near absence of any free-flowing water; thus, the microorganism is almost directly in contact with gaseous oxygen in the air [1]. Among the advantages of this technique, Archana et al. [2] pointed out the economy of space due to a lower water volume which also avoids contamination taking into account the lower moisture levels; the simplicity of the fermentation media; the simplicity of machinery, equipment, and/or control systems, with the consequent lower investment in capital; the reported higher product yields; the reduced energy demand; and also the easier scale-up of processes. Nevertheless, these authors also mentioned some drawbacks or limitations such as the smaller amount of microorganisms capable of growing in these reduced moisture levels; the higher requirements of humidity, flow air, free oxygen transfer, and removal of generated $\mathrm{CO}_{2}$; as well as the need for pretreatment of some solid substrates. In spite of these inconveniences, it has been an increasing use of SSF in the last decades for the production of microbial enzymes [3].

Concerning that the microorganisms can be employed in SSF processes and although several bacteria, yeast, and filamentous fungi have been reported to produce xylanolytic enzymes in SSF, filamentous fungi were the most widely exploited because of their ability to grow on complex solid substrates, producing a wide range of extracellular enzymes [4], including xylanases [EC.3.2.1.8], whose levels in fungi are generally much higher than those in yeast and bacteria [3]. On an industrial scale, xylanases are produced mainly by Aspergillus and Trichoderma spp. [5]. Importance of microbial xylanases has increased in the present scenario due to their immense biotechnological applications in diverse sectors such as food, animal feed, paper, and pulp industries as well as for bioconversion of lignocellulosic waste into value-added chemicals [6]. Thus, xylanases find applications in the food and beverage industries for the production of bakery goods, coffee, starch, plant oil, and juice manufacture; feedstock improvement, particularly for increasing the animal feed digestibility; and also for the quality improvement of lignocellulosic residues [7]. In this later scenario, xylanases are responsible for hydrolysis or bioconversion of lignocelluloses to sugars, firstly attacking the internal main-chain linkages and subsequently releasing xylosyl residues by endwise attack of xylooligosaccharides [8].

However, for commercial production of biochemicals, the production costs must be reduced by finding economical and commercially available media, such as industrial or agricultural byproducts [9]. On the other hand, the existence of pollution problems which are associated to agroindustrial wastes and the scarce number of proper places for their disposal, the costlier treatment options, and also the increased need to save valuable resources have forced to encourage the use of waste for their bioconversion into high-value industrially useful products [6]. Among these residues, corncob obtained from maize is a potentially useful raw material for obtaining value-added products, whose importance lies on the high production of this cereal, more than $8.75 \times 10^{8}$ t in 2012 [10], as the main diet contributor on several countries such as Mexico or Brazil. Due to its lignocellulosic character, corncob is made up mainly of cellulose, hemicelluloses, and lignin.

In the hemicellulosic fraction, xylan is the major polysaccharide of agricultural wastes comprising up to $20-35 \%$ dry weight [11]. Xylan is a heterogeneous polysaccharide consisting of a backbone chains of $\beta$-1,4-linked $\beta$-D-xylopyranose units with a small fraction of arabinose and glucuronic and arabinoglucuronic acids linked to the D-xylose backbone [12]. The use of xylan for large-scale production of xylanases is uneconomical because of its cost; hence, the use of cost-effective substrates such as hemicellulosic material is highly 
recommended [8]. In particular, the high xylan content of corncob, up to $30 \%$ according to Prade [13], makes this waste a largely available renewable source of xylose for obtaining highvalue-added products by means of biotechnological processes. Although acid and hydrothermal treatments have shown good efficiencies, the mild conditions of the enzymatic hydrolysis offer the advantage of avoiding the generation of microbial inhibitors and toxic compounds as hydroxymethylfurfural and furfural coming from the thermal degradation of carbohydrates. Microbial xylanases are the preferred catalysts for the hydrolysis of xylan, mainly due to their higher specification, milder reaction conditions, or negligible substrate losses [6].

Considering that the cost of an enzyme is one of the main factors to determine the economics of a process, reducing the costs of enzyme production by optimizing the fermentation medium is the main goal of basic research for industrial applications [14]. Thus, the aim of this work was to optimize the production of xylanases by using different microorganisms and testing physic properties (moisture content and bed loading) and concentrations of salt solution used. Finally, the process was scaled up in a horizontal tube bioreactor studding the effect of aeration rate on xylanase activity.

\section{Materials and Methods}

\section{Microorganisms}

The following microorganisms Aspergillus niger CECT 2700, A. niger CECT 2915, A. niger CECT 2088, Aspergillus terreus CECT 2808, and Rhizopus stolonifer CECT 2344, all of them from the Spanish Type Culture Collection, were used in the present study. Cultures were grown on potato dextrose agar (PDA) slants at $30^{\circ} \mathrm{C}$ for 7 days and stored at $4{ }^{\circ} \mathrm{C}$.

\section{Screening of Microorganisms for Xylanase Production Under Solid-State Fermentation}

Static experiments were carried out in 250-mL Erlenmeyer flasks containing 10-g (dry weight) powdered corncob substrates moistened with a concentrated nutrient salt solution to soak corncobs to $70 \%(w / w)$ moisture level (equivalent to an initial substrate to solution ratio of 1:2.4 (w/v)). The salt solution contained $2.4 \mathrm{~g} / \mathrm{L}\left(\mathrm{NH}_{4}\right)_{2} \mathrm{SO}_{4}, 3.0 \mathrm{~g} / \mathrm{L} \mathrm{NaNO}_{3}, 1.5 \mathrm{~g} / \mathrm{L} \mathrm{KH}_{2} \mathrm{PO}_{4}$, $0.3 \mathrm{~g} / \mathrm{L} \mathrm{CaCl}{ }_{2} \cdot 2 \mathrm{H}_{2} \mathrm{O}, 3 \mathrm{~g} / \mathrm{L}$ yeast extract, and $3 \mathrm{~g} / \mathrm{L}$ glucose. The flasks were sterilized at 100 ${ }^{\circ} \mathrm{C}$ for $1 \mathrm{~h}$ in autoclave (Trade Raypa SL, Terrassa, Barcelona) and, after cooling, inoculated with a spore suspension prepared by adding $0.1 \%$ peptone water with $0.05 \%$ Tween 80 to slant cultures. One milliliter of $1 \times 10^{6}$ spores/g dry corncob was inoculated to each flask. Cultures for each microorganism were incubated statically at $30{ }^{\circ} \mathrm{C}$ in a $\mathrm{H}_{2} \mathrm{O}$-saturated atmosphere. Every $24 \mathrm{~h}$, the flasks were shaken by hand to prevent aggregation of solids.

\section{Effect of Nitrogen and Carbon Sources}

A. niger CECT 2700 was used in this study since it was the best xylanase producer among the previously studied strains. The conditions of fermentations were similar to those described above but changing $\left(\mathrm{NH}_{4}\right)_{2} \mathrm{SO}_{4}$ and $\mathrm{NaNO}_{3}$ concentrations during the effect of nitrogen source. Thus, $1 \mathrm{~g} / \mathrm{L}$ of nitrogen was added to salt solutions in ratios $0: 1,1: 1,2: 1,3: 1$, and 1:0 $(w / w)$ of $\mathrm{NaNO}_{3} /\left(\mathrm{NH}_{4}\right)_{2} \mathrm{SO}_{4}$. In a particular experiment, the salt solution was replaced by vinasses from the campaign of 2007, obtained after the distillation of lees. These vinasses were kindly supplied by the certified brand of origin of Valdeorras (Ourense), Spain, and stored at 4 ${ }^{\circ} \mathrm{C}$. In this case, vinasses were added to corncobs until obtaining $70 \%$ moisture. 
The study of the carbon source was carried out using a $\mathrm{NaNO}_{3}$ to $\left(\mathrm{NH}_{4}\right)_{2} \mathrm{SO}_{4}$ ratio of $3: 1$ $(w / w)$, equivalent to 4.6 and $1.2 \mathrm{~g} / \mathrm{L}$, respectively, since although no significant differences were observed during the study of nitrogen source on fermentation, this ratio maintained a slightly higher value of xylanase activity. The study involved the use of salt solution without glucose or xylose as control medium and with glucose or xylose, both in the following concentrations: 5,10 , and $20 \mathrm{~g} / \mathrm{L}$. Also, the influence of the yeast extract using 0,3 , and 6 $\mathrm{g} / \mathrm{L}$ was tested on xylanase activity.

\section{Experimental Designs}

The influences of operational conditions (experimental design 1) and salt concentration (experimental design 2) on xylanase activity were studied according to statistical experimental designs (Design-Expert version 5.0, Stat-Ease, Inc., Minneapolis, USA), and results were evaluated by the corresponding response surface methodology using Statistic software package version 5.0 (StatSoft, USA) considering the SS residual to evaluate the significance of the effects and the model.

Experiments were performed in experimental design 1 using Erlenmeyer flasks with different bed loadings (BLs) $(5,10$, or $15 \mathrm{~g}$ of grounded corncob) and moisture contents (MCs) $(1: 2.4,1: 3,1: 3.6(w / v))$. A salt solution containing $4.6 \mathrm{~g} / \mathrm{L} \mathrm{NaNO}_{3}, 1.2 \mathrm{~g} / \mathrm{L}\left(\mathrm{NH}_{4}\right)_{2} \mathrm{SO}_{4}$, $4.5 \mathrm{~g} / \mathrm{L} \mathrm{KH}_{2} \mathrm{PO}_{4}, 0.3 \mathrm{~g} / \mathrm{L} \mathrm{CaCl} 2 \cdot 2 \mathrm{H}_{2} \mathrm{O}$, and $3 \mathrm{~g} / \mathrm{L}$ yeast extract was employed to moisten the corncob employed as carbon source.

Table 1 provides information about the factors and levels used. The influence of both operational variables (BL and $\mathrm{MC}$ ) was tested on three levels $(-1,0,1)$ in a $3 * *(2-0)$ full factorial design. The standardized (coded) dimensional variables employed, having variation limits $(-1,1)$, were defined as $x_{1}$ (coded BL) and $x_{2}$ (coded MC).

The influence of salt concentration was tested in experimental design 2 in a $2^{3}$ rotatable central composite design at five levels with six start points $(\alpha= \pm 1.67)$ and three replicates at the center points. Concentrations of minerals of nitrogen $(\mathrm{N})$, phosphorus $(\mathrm{P})$, and calcium (Ca) were studied, as shown in Table 1 . Yeast extract $(3 \mathrm{~g} / \mathrm{L})$ was placed in all salt solutions and used to moisten the substrate with an initial MC of 1:3.6 (w/w) and a BL of $5 \mathrm{~g}$ (according to the optima value achieved in experimental design 1).

All experiments were carried out in randomized run order for 5 days. These designs allowed the estimation of the significance of the parameters and their interactions. Data from the

Table 1 Factors and levels used to study the influence of operational conditions (experimental design 1) and salt concentration (experimental design 2) on xylanase activity

Levels

(a) Design 1

Factor

MC

$-1$

0

1

BL

2.4

3.0

3.6

5.0

10

15

(b) Design 2

\begin{tabular}{clllll} 
Salts $(\mathrm{g} / \mathrm{L})$ & -1.673 & -1 & 0 & 1 & 1.673 \\
$\mathrm{~N}$ & 0 & 0.4 & 1 & 1.6 & 2 \\
$\mathrm{P}$ & 0 & 0.4 & 1 & 1.6 & 2 \\
$\mathrm{Ca}$ & 0 & 0.2 & 0.5 & 0.8 & 1 \\
\hline
\end{tabular}

$M C$ moisture content, $B L$ bed loading 
factorial design were subjected to a second-order multiple regression analysis using leastsquare regression methodology to obtain the parameters of the mathematical models. The interrelationship between dependent and operational variables was established by a model including linear, interaction, and quadratic terms:

$$
\begin{aligned}
y= & b_{0}+b_{1} \cdot x_{1}+b_{2} \cdot x_{2}+b_{3} \cdot x_{3}+b_{11} \cdot x_{1}^{2}+b_{22} \cdot x_{2}{ }^{2}+b_{33} \cdot x_{3}^{2}+b_{12} \cdot x_{1} \cdot x_{2} \\
& +b_{13} \cdot x_{1} \cdot x_{3}+b_{23} \cdot x_{2} \cdot x_{3}
\end{aligned}
$$

where $y$ represents the dependent variable (xylanase activity), $b$ denotes the regression coefficients (calculated from experimental data by multiple regression using the least-square method), and $x$ denotes the independent variables (BL and MC in experimental design 1 and $\mathrm{N}, \mathrm{P}$, and $\mathrm{Ca}$ concentrations in experimental design 2).

The quality of the polynomial model equations was statistically judged by the coefficient of determination $\left(R^{2}\right)$, and its statistical significance was determined by an $F$ test. The significance of the regression coefficients was tested by the Student's $t$ test and by the probability $(p=0.05)$.

Optimization was performed using the solver routine based on the Newton method. These analyses were performed using Microsoft Excel 2000 (Microsoft Corporation, Redmond, WA, USA, 1999) software.

\section{Corncob Pretreatments and Chemical Characterization}

Corncobs from the campaign of 2010 were collected in Mondariz (Pontevedra, Spain), dried at room temperature, and milled and sieved to get a particle size $<5 \mathrm{~mm}$. Aliquots from the homogenized lot were submitted to different pretreatments to evaluate the improvement on the production of xylanases by A. niger CECT 2700.

Destarching Milled corncob was destarched by suspending $100 \mathrm{~g}$ of material in 1,000 $\mathrm{mL}$ of water and $10 \mathrm{~mL}$ of Termamyl $120 \mathrm{~L}$ (Novozymes, Bagsvaerd, Denmark). The mixture was stirred for $1.5 \mathrm{~h}$ in a boiling water bath. The suspension was centrifuged at $2,755 \times \mathrm{g}$ for $10 \mathrm{~min}$, rejecting the supernatant; meanwhile, the residue was washed with hot water and centrifuged again twice. The final residue was dried for $24 \mathrm{~h}$ at $<40$ ${ }^{\circ} \mathrm{C}$ according to the method proposed by Saulnier et al. [15] and subjected to different pretreatments.

Autoclaving Destarched corncob was kept in contact with water $(4: 1$ corncob/water $(w / v))$ for $1 \mathrm{~h}$ in order to allow the penetration of water into the material and heated for $2 \mathrm{~h}$ at $130{ }^{\circ} \mathrm{C}$ (which means a severity factor of $\log \mathrm{R}_{0}=2.96$ ) in a laboratory autoclave (Trade Raypa SL, Terrassa, Barcelona, Spain), following an adaptation of the methodology described by Bonnin et al. [16]. Finally, corncob was dried at room temperature.

Alkaline Pretreatments The first alkaline pretreatment was given by preparing $15 \%(\mathrm{w} / \mathrm{v})$ of destarched corncob in $1 \mathrm{M} \mathrm{NaOH}$ and further incubation for $12 \mathrm{~h}$ at room temperature. The second pretreatment was carried out by preparing slurry of destarched corncob in $15 \%$ ammonia solution $(1: 4.5(\mathrm{w} / \mathrm{v}))$ and autoclaved at $121^{\circ} \mathrm{C}$ for $1 \mathrm{~h}$. After alkaline pretreatments, both substrates were washed independently with distilled water until neutrality and dried in oven at $80{ }^{\circ} \mathrm{C}[6]$. 
Autoclaving Microwave Destarched corncob was weighted, and MC was adjusted to $25 \%$ $(w / w)$ by adding distilled water at room temperature. The mixture was kept in contact for $1 \mathrm{~h}$ in order to allow the penetration of water. Samples were heated at $130{ }^{\circ} \mathrm{C}$ for $2 \mathrm{~h}$ in autoclave and submitted to microwave irradiation $(540 \mathrm{~W})$ for 3 min $\left(M A R S X p r e s s^{\mathrm{TM}}\right.$, CEM Corporation, NC, USA). Finally, the samples were dried at room temperature according to Pang et al. [17].

The composition of raw and treated corncob was quantified after submitting samples of the material to moisture determination and quantitative acid hydrolysis in two stages according to the method of Vázquez et al. [18]. In brief, the first acid treatment was performed with $72 \%$ sulfuric acid at $30{ }^{\circ} \mathrm{C}$ for $1 \mathrm{~h}$ and the second one after dilution of the media to $3 \%$ sulfuric acid at $121{ }^{\circ} \mathrm{C}$ for $1 \mathrm{~h}$. The solid residue obtained after hydrolysis was considered as Klason lignin.

\section{Xylanase Production in Horizontal Tube Bioreactor}

Corncob (20 g) was moistened with a mineral salt solution (containing $1.1 \mathrm{~g} / \mathrm{L}$ of nitrogen corresponding to $5.0 \mathrm{~g} / \mathrm{L} \mathrm{NaNO}_{3}$ and $1.3 \mathrm{~g} / \mathrm{L}\left(\mathrm{NH}_{4}\right)_{2} \mathrm{SO}_{4}, 4.5 \mathrm{~g} / \mathrm{L} \mathrm{KH}_{2} \mathrm{PO}_{4}$ and $3 \mathrm{~g} / \mathrm{L}$ yeast extract) using an initial ratio of 1:3.6 (w/v). Substrate was sterilized in an Erlenmeyer flask at $100{ }^{\circ} \mathrm{C}$ for $1 \mathrm{~h}$ in autoclave (Trade Raypa SL, Terrassa, Barcelona), inoculated with $1 \mathrm{~mL}$ of a spore suspension prepared in a concentration enough to provide $1 \times 10^{6}$ spores/g dry corncob, and aseptically placed in a horizontal heat-sterilized double-jacketed glass column reactor (26.3-cm length and 2.62-cm diameter). This amount of corncob covered half of the column, thus increasing the superficial area in contact with air. Fermentations were performed at different aeration rates $(0.1,0.2$, and $0.4 \mathrm{~L} / \mathrm{min})$, kept at $30^{\circ} \mathrm{C}$ by circulating hot water using a thermostatic water bath and under static conditions. Air was passed through a filter and fed into the reactor through a perforated aluminum cylinder fitted inside the column. Moisture was replenished by bubbling the inlet air into sterile water.

\section{Enzyme Extraction and Analysis}

Crude extracts were obtained by adding distilled water $(10-\mathrm{mL} / \mathrm{g}$ dry solid substrate) to each flask and incubated for $1 \mathrm{~h}, 200 \mathrm{rpm}$ at $30{ }^{\circ} \mathrm{C}$ [3]. The contents were centrifuged at $2,755 \times \mathrm{g}$ for 15 min (Ortoalresa, Consul 21, EBA 20, Hettich Zentrifugen, Germany) and filtered, and the enzyme extracts were stored at $-20^{\circ} \mathrm{C}$ for further analysis. $\mathrm{pH}$ of the enzyme extracts was measured (pH meter BASIC 20+, CRISOL, Alella, Barcelona, Spain). Reducing sugars were assessed by the dinitrosalicylic acid method described by Miller [19]. Glucose, xylose, arabinose, and acids (acetic, oxalic, citric, and malic) were analyzed by high-performance liquid chromatography (HPLC) (Agilent, model 1200, Palo Alto, CA) using a refractive index detector with an Aminex HPX-87H ion exclusion column (Bio-Rad; $300 \times 7.8 \mathrm{~mm}, 9-\mu \mathrm{m}$ particles) with a guard column, eluted with $0.003 \mathrm{M}$ sulfuric acid at a flow rate of $0.6 \mathrm{~mL} / \mathrm{min}$ at $50{ }^{\circ} \mathrm{C}$.

\section{Enzymatic Activities}

Xylanase activity was assayed by determining the release of reducing sugars from $1 \%(w / v)$ of boiled oat spelt xylan (Sigma-Aldrich, USA) in 50-mM sodium phosphate buffer $\mathrm{pH} 6$, incubating at $50{ }^{\circ} \mathrm{C}$ for $10 \mathrm{~min}$ [20]. Cellulase activity was assayed by determining the reducing sugars released from $1 \times 5.5 \mathrm{~cm}^{2}(50 \pm 0.1 \mathrm{mg})$ filter paper strip Whatman No. 1 (Healthcare, Buckinghamshire, UK) at $\mathrm{pH} 4.8$ (50-mM sodium citrate buffer) incubating at 
$50{ }^{\circ} \mathrm{C}$ for $60 \mathrm{~min}$ [21]. Cellobiase activity was assayed by determining the release of reducing sugars from $10 \mathrm{mM}$ cellobiose at $\mathrm{pH} 4.8\left(50 \mathrm{mM}\right.$ sodium citrate) at $50{ }^{\circ} \mathrm{C}$ for $30 \mathrm{~min}$ [21]. The reactions were dinitrosalicylic acid (DNS) stopped and heated in a boiling water bath for $5 \mathrm{~min}$. Reducing sugars were assayed by using DNS method measuring the absorbance at $540 \mathrm{~nm}$ [19]. Feruloyl esterase activity was assayed by determining the ferulic acid released from $1.33 \mathrm{mM}$ ethyl ferulate in 50 -mM sodium phosphate buffer $\mathrm{pH} 6.0$ with $1 \%(w / v)$ ethanol. The reaction was stopped using $0.35 \mathrm{M} \mathrm{H}_{2} \mathrm{SO}_{4}$ [22], and samples were filtered through $0.2-\mu \mathrm{m}$ syringe filter for ferulic acid measurement by HPLC (Agilent, model 1200, Palo Alto, CA, USA) equipped with an Agilent Zorbax SB-Aq C18 column $(4.6 \times 150$ $\mathrm{mm}, 5-\mu \mathrm{m}$ particles) with a guard column. Injection volume of each sample was $20 \mu \mathrm{L}$. Ferulic acid was separated at $35{ }^{\circ} \mathrm{C}$ with a gradient elution program at the flow rate of 1 $\mathrm{mL} / \mathrm{min}$. The mobile phase was a mixture of solvent A $(2.5 \%(v / v)$ formic acid in water $)$ and solvent B (100\% methanol HPLC grade). The gradient elution program was from 0 to $48 \%$ of solvent B $(0-35 \mathrm{~min})$, from 48 to $100 \%$ of solvent B $(35-40 \mathrm{~min})$, and $100 \%$ of solvent B (40-65 min). The UV detector was set at $276 \mathrm{~nm}$.

One unit $(\mathrm{U})$ of enzymatic activity is defined as the amount of enzyme required to release $1 \mu \mathrm{mol}$ of reducing sugar as xylose, glucose, or ferulic acid equivalent per minute under the assay conditions. The unit "U/g dcc" denotes the enzymatic activity in international unit produced per gram of dry corncob. All the experiments were done in triplicate.

Field Emission Scanning Electron Microscopy (FE-SEM)

Scanning electron microscopy (SEM) was employed to study the morphological changes of corncob before or after treatments.

The dry corncob was mounted onto aluminum stubs, and samples were coated with gold in Sputter Coater (Sputtering Emitech K550X, Quorum Technologies, Kent, UK) for 3 min. Finally, the samples were observed and photographed in an FE-SEM system (Model JSM6700F, Jeol, Japan).

\section{Results and Discussion}

Screening of Microorganisms

Aspergillus strains have been widely reported in bibliography for the production of xylanases. For instance, Delabona et al. [23] produced 1,285-U/g xylanases and 96.0-U/g $\beta$-glucosidase from wheat bran with $50 \%$ initial MC using A. niger P47C3. Pal and Khanum [3] increased this activity of xylanases up to 2,596 U/g using A. niger DFR-5 in a medium containing wheat bran and soybean cake at a ratio of $70: 30$, moistened to $70 \%$ with a mineral salt solution. Meanwhile, Lakshmi et al. [8] using A. terreus MTCC 8661 produced up to $115 \mathrm{U} / \mathrm{g}$ from palm oil fiber. On the basis of these reports, five filamentous fungi A. niger CECT 2700, A. niger CECT 2915, A. niger CECT 2088, A. terreus CECT 2808, and $R$. stolonifer CECT 2344 were screened for the production of xylanases using corncob as substrate. One additional experiment was performed, as control, growing A. niger CECT 2700 in the absence of salts. Table 2 compiles xylanase, cellulase, and cellobiase activities measured after 3 or 5 days of fermentation, as well as the final $\mathrm{pH}$ values.

All microorganisms showed capacity to develop on corncob moistened with salt solutions. Strong mycelium formation and substrate colonization were evident after $24 \mathrm{~h}$ of incubation, and an appreciable enzyme production was observed in all cases with very low levels of 


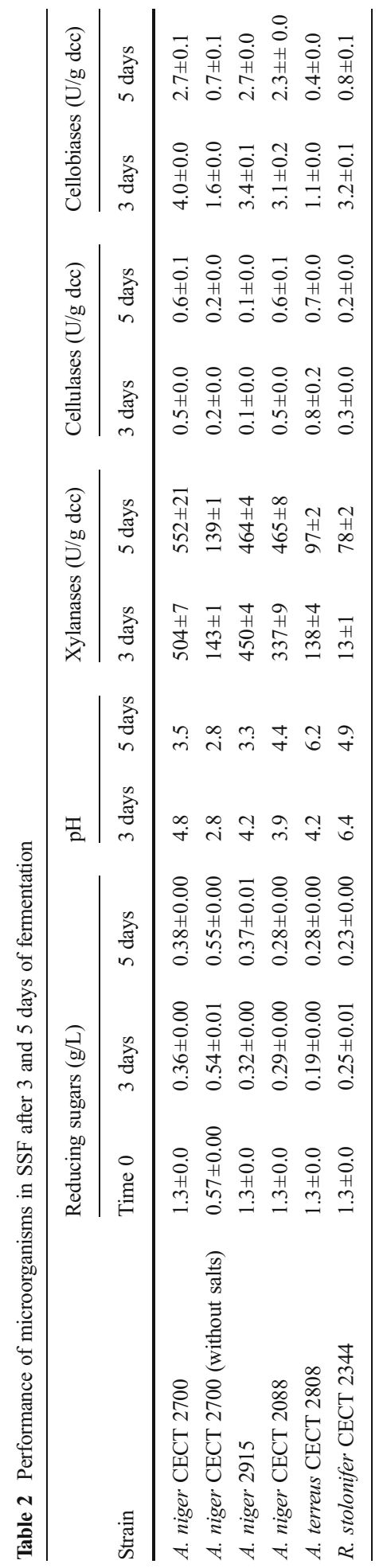


reducing sugars, which indicates a rapid utilization of the products of hydrolysis by the fungus. Xylanase activity ranged from $13 \pm 1$ to $504 \pm 7$ at the third day and $78 \pm 2$ to $552 \pm 21$ at the fifth day, showing that the maximum xylanase activity was obtained after 5 days of fermentation. A. niger strains were the best xylanase producers, and A. niger CECT 2700 was the best strain, producing up to $504 \pm 7 \mathrm{U} / \mathrm{g}$ dcc and $552 \pm 21 \mathrm{U} / \mathrm{g}$ dec after 3 and 5 days, respectively. $R$. stolonifer CECT 2344 was the microorganism which produced less amounts of xylanases, obtaining $13 \pm 1$ and $78 \pm 2 \mathrm{U} / \mathrm{g}$ dcc at the third and fifth days, respectively. Additionally, all microorganisms produced small amounts of cellulases (ranging from $0.1 \pm 0.01$ to $0.8 \pm 0.02 \mathrm{U} /$ $\mathrm{g} \mathrm{dcc})$ and cellobiases $(0.4 \pm 0.04$ to $4.0 \pm 0.02 \mathrm{U} / \mathrm{g} \mathrm{dcc})$.

The need of using salts was reflected considering that $A$. niger CECT 2700 fermented in absence of salts only produced $143 \pm 1-139 \pm 1$ U xylanases/g dcc after 3-5 days of fermentation, respectively. The production of other enzymes was also drastically reduced to $0.2 \pm 0.02$ $\mathrm{U}$ cellulases/g dcc and $0.7 \pm 0.1$ to $1.6 \pm 0.02 \mathrm{U}$ cellobiases/g dcc.

Table 2 also includes the final values of $\mathrm{pH}$ measured after 3 and 5 days of fermentation. Starting with a $\mathrm{pH}$ value of 4.54 , no correlation was observed between $\mathrm{pH}$ and enzyme activities, with final $\mathrm{pH}$ values ranging from 3.3 (A. niger CECT 2915) to 6.2 (A. terreus CECT 2808). This value decreased to 2.8 in $A$. niger CECT 2700 grown in the absence of salts probably because of a higher production of carboxylic acids [24].

\section{Influence of Nitrogen and Carbon Sources}

A. niger CECT 2700 was selected from previous experiments as the best xylanase producer and employed to study the influence of the nitrogen source. The addition of nitrogen is usually an important requirement considered since the amounts of nitrogen and/or essential nutrients in lignocellulosic substrates are often too low to support good growth and enzyme production [6]. Hence, Kulkarni et al. [5] reported that nitrogen source mediates regulation of microbial growth and metabolism, thus being an essential requirement for growth and production of enzymes. Consequently, typical media for the production of xylanases by fungi contain, in addition to the inducing substrate, several mineral salts (e.g., $\mathrm{KH}_{2} \mathrm{PO}_{4}, \mathrm{MgSO}_{4}, \mathrm{CaCl}_{2}, \mathrm{NH}_{4}^{+}$ salts, and $\mathrm{NO}_{3}^{-}$salts) and some metallic ions (e.g., $\mathrm{Fe}^{2+}, \mathrm{Co}^{2+}, \mathrm{Zn}^{2+}$ ); often, complex nitrogen sources are added as well [25]. Table 3 presents the results of xylanase activity obtained from A. niger CECT 2700 under different $\mathrm{NaNO}_{3} /\left(\mathrm{NH}_{4}\right)_{2} \mathrm{SO}_{4}$ ratios, after 5 or 7 days of incubation. Additionally, $1.5 \mathrm{~g} / \mathrm{L} \mathrm{KH}_{2} \mathrm{PO}_{4}$ and $3 \mathrm{~g} / \mathrm{L}$ yeast extract were supplied in all fermentation broth, since according to Senthilkumar et al. [11], $\mathrm{KH}_{2} \mathrm{PO}_{4}$ can be added for its buffering activity on

Table 3 Xylanase production by A. niger CECT 2700 as a function of nitrogen ratio after 5 and 7 days of fermentation

\begin{tabular}{|c|c|c|c|c|c|c|c|}
\hline \multirow[b]{2}{*}{$\mathrm{NaNO}_{3} /\left(\mathrm{NH}_{4}\right)_{2} \mathrm{SO}_{4}$} & \multicolumn{3}{|c|}{ Reducing sugars $(\mathrm{g} / \mathrm{L})$} & \multicolumn{2}{|l|}{$\mathrm{pH}$} & \multicolumn{2}{|c|}{ Xylanase (U/g dcc) } \\
\hline & Time 0 & 5 days & 7 days & 5 days & 7 days & 5 days & 7 days \\
\hline $0: 1$ & $1.4 \pm 0.0$ & $0.72 \pm 0.36$ & $0.47 \pm 0.01$ & 2.9 & 2.8 & $638 \pm 17$ & $510 \pm 36$ \\
\hline $1: 1$ & $1.4 \pm 0.0$ & $0.48 \pm 0.01$ & $0.34 \pm 0.00$ & 3.8 & 3.6 & $654 \pm 28$ & $426 \pm 30$ \\
\hline $2: 1$ & $1.4 \pm 0.0$ & $0.39 \pm 0.00$ & $0.32 \pm 0.01$ & 3.5 & 3.5 & $651 \pm 27$ & $496 \pm 35$ \\
\hline $3: 1$ & $1.4 \pm 0.0$ & $0.42 \pm 0.02$ & $0.41 \pm 0.01$ & 3.5 & 3.4 & $655 \pm 12$ & $506 \pm 11$ \\
\hline $1: 0$ & $1.4 \pm 0.0$ & $0.42 \pm 0.01$ & $0.35 \pm 0.00$ & 4.0 & 3.9 & $405 \pm 4$ & $214 \pm 60$ \\
\hline Vinasses & $1.1 \pm 0.0$ & $0.65 \pm 0.01$ & $0.62 \pm 0.01$ & 3.3 & 3.1 & $155 \pm 19$ & $69 \pm 18$ \\
\hline
\end{tabular}


the medium; meanwhile, yeast extract assists with spore germination and initial growth. Cellulase and cellobiase activities were not determined due to the low values achieved in previous experiments. Xylanase activity was higher on the fifth day than on the seventh day, obtaining $155 \pm 19-655 \pm 12 \mathrm{U} / \mathrm{g}$ dcc and $69 \pm 18-510 \pm 36 \mathrm{U} / \mathrm{g}$ dcc, respectively.

There were no significant differences on the results, except for the $\mathrm{NaNO}_{3} /\left(\mathrm{NH}_{4}\right)_{2} \mathrm{SO}_{4}$ ratio of 1:0 which presented lower xylanase activity $(405 \pm 4$ and $214 \pm 60 \mathrm{U} / \mathrm{g}$ dcc, after 5 and 7 days, respectively). Using the $\mathrm{NaNO}_{3} /\left(\mathrm{NH}_{4}\right)_{2} \mathrm{SO}_{4}$ ratio of $0: 1$, although presented a good xylanase activity, the final $\mathrm{pH}$ of the fermentation extract was only 2.8. The nitrogen source can significantly affect the $\mathrm{pH}$ of the medium during the course of fermentation, thereby influencing the microbial metabolism [26]. Considering the difficulty to control the $\mathrm{pH}$ in solid-state cultures, these results showed the importance of mixing both nitrogen sources to maximize xylanase production and to keep the $\mathrm{pH}$ of the fermentation broth higher.

Additionally, the influence of yeast extract $(0,3$, and $6 \mathrm{~g} / \mathrm{L}$ ) was also considered (data not shown), taking into account that yeast extract is the most commonly used complex nitrogen source in laboratory-scale fermentations probably due to the purine and pyrimidine bases and B vitamins, which lead to good yields for enzyme production [25, 27]. The results showed significant effect $(p<0.05)$ on xylanase activity, resulting in a strong decrease in its absence; conversely, higher xylanase production was obtained using $3 \mathrm{~g} / \mathrm{L}$. Consequently, the $\mathrm{NaNO}_{3} /$ $\left(\mathrm{NH}_{4}\right)_{2} \mathrm{SO}_{4}$ ratio of $3: 1$ with $3 \mathrm{~g} / \mathrm{L}$ yeast extract was considered as the best condition for further experimentation.

Finally, an additional experiment was carried out using vinasses as source of nitrogen and essential nutrients. Vinasses are the main liquid wastes of the alcohol industry from the distillation process of lees and low-quality wines. This by-product has been effectively used as economic nutrient for some biotechnological processes including the production of citric acid by $A$. niger strains by SmF [27]. However, in this case, vinasses did not contribute to an increase on xylanase activity; on the contrary, during this fermentation, the enzyme production decreased 4.2-fold relatively to the activity of xylanases using the $\mathrm{NaNO}_{3} /\left(\mathrm{NH}_{4}\right)_{2} \mathrm{SO}_{4}$ ratio of $3: 1$. This could be attributed to the absence of enough amount of nitrogen to perform an SSF process [28]. The high-nitrogen requirements were highlighted considering the results of Senthilkumar et al. [11] who predicted maxima xylanase yields of $931 \mathrm{U} / \mathrm{g}$ of substrate in optimized medium composed of $7.0 \mathrm{~g} / \mathrm{L}$ of $\mathrm{NaNO}_{3}, 1.0 \mathrm{~g} / \mathrm{L}$ of $\mathrm{KH}_{2} \mathrm{PO}_{4}, 0.5 \mathrm{~g} / \mathrm{L}$ of $\mathrm{MgSO}_{4}$, and $5.0 \mathrm{~g} / \mathrm{L}$ of yeast extract.

To check if a small amount of quickly assimilable sugars could help spore germination and fungal growth for a higher enzyme production, low amounts of glucose and xylose were included in the formulation of the salt solution. Table 4 presents the results of xylanase activity

Table 4 Effect of carbon source on xylanase production by A. niger CECT 2700 after 5 days of fermentation

\begin{tabular}{|c|c|c|c|c|}
\hline \multirow[b]{2}{*}{ Carbon source } & \multicolumn{2}{|c|}{ Reducing sugars $(\mathrm{g} / \mathrm{L})$} & \multirow{2}{*}{$\begin{array}{l}\mathrm{pH} \\
5 \text { days }\end{array}$} & \multirow{2}{*}{$\begin{array}{l}\text { Xylanase }(\mathrm{U} / \mathrm{g} \text { dcc }) \\
5 \text { days }\end{array}$} \\
\hline & Time 0 & 5 days & & \\
\hline Glucose, $5 \mathrm{~g} / \mathrm{L}$ & $1.2 \pm 0.0$ & $0.4 \pm 0.0$ & 3.6 & $975 \pm 2$ \\
\hline Glucose, $10 \mathrm{~g} / \mathrm{L}$ & $2.5 \pm 0.0$ & $0.4 \pm 0.0$ & 3.6 & $957 \pm 22$ \\
\hline Glucose, $20 \mathrm{~g} / \mathrm{L}$ & $5.0 \pm 0.0$ & $0.4 \pm 0.0$ & 3.5 & $879 \pm 37$ \\
\hline Xylose, $5 \mathrm{~g} / \mathrm{L}$ & $1.5 \pm 0.0$ & $0.4 \pm 0.0$ & 3.4 & $977 \pm 25$ \\
\hline Xylose, 10 g/L & $3.0 \pm 0.0$ & $0.4 \pm 0.0$ & 3.6 & $925 \pm 77$ \\
\hline Xylose, $20 \mathrm{~g} / \mathrm{L}$ & $5.9 \pm 0.0$ & $0.4 \pm 0.0$ & 3.4 & $764 \pm 22$ \\
\hline $0 \mathrm{~g} / \mathrm{L}$ & $0.5 \pm 0.0$ & $0.4 \pm 0.0$ & 3.7 & $1,074 \pm 31$ \\
\hline
\end{tabular}


obtained in flasks under different concentrations of glucose and xylose after 5 days of fermentation. The presence of glucose or xylose showed a significant effect $(p<0.05)$ on xylanase activity. The results showed that the addition of glucose or xylose in the salt solution decreased the amount of xylanase synthesized, since the xylanase activity decreased respected to the value of $1,074 \pm 31 \mathrm{U} / \mathrm{g}$ obtained in the control carried out without sugars. These results are in agreement with the findings of Benedetti et al. [29], who indicated that glucose and xylose at $2 \%$ have a repressor effect of the xylanase production by $A$. niger FCUP1. The effect of xylose was more detrimental than the influence of glucose. Consequently, further experiments were performed in the absence of sugars. The 1.6-fold increase (from 655 to 1,074 U/g) of the xylanase production obtained when the optimal supplementations of $\mathrm{N}$ salts and yeast extract were simultaneously applied was noticeable.

\section{Moisture Content and Bed Loading}

Statistically planned experiments reduce the number of experiments by developing a specific design of experiments which also minimizes the error in determining the values for significant parameters [30]. Thus, two consecutive experimental designs were conducted. First, two operational conditions, $\mathrm{MC}$ and $\mathrm{BL}$, were studied to optimize the production of xylanases by response surface methodology.

Table 5 shows the set of experimental conditions assayed, expressed in terms of coded variables, as well as the experimental data obtained for xylanase activity and the final $\mathrm{pH}$. A multiple regression analysis was carried out to describe the relationship among independent and dependent variables. According to this analysis, a quadratic model could be well adjusted to explain the variation of xylanase activity as a function of the MC and BL.

Table 6 lists the regression coefficients and the statistical significance of each coefficient based on the Student's $t$ test and probability $(p)$ values. Although the coefficients obtained are empirical and cannot be associated with physical or chemical changes, they are very useful to predict the results of untested operational conditions [31]. A larger magnitude of $t$ test and smaller $p$ value denotes greater significance of the corresponding coefficient [32]. Table 6 also shows the statistical parameters $\left(R^{2}, R^{2}\right.$ adjusted, $F$, and the significance level based on the $F$

Table 5 Operational conditions considered in this study expressed in terms of the coded independent variables (dimensionless moisture content $x_{1}$ and dimensionless bed loading $x_{2}$ ) and experimental results achieved for the dependent variable (xylanase activity $\left.(\mathrm{U} / \mathrm{g} \mathrm{dcc}) y_{1}\right)$

\begin{tabular}{|c|c|c|c|c|c|c|}
\hline \multirow[b]{3}{*}{ Runs } & \multicolumn{2}{|l|}{ Coded variables } & \multirow[b]{3}{*}{$\mathrm{pH}$} & \multicolumn{2}{|c|}{ Xylanase activity (U/g dcc) } & \multirow[t]{3}{*}{ Relative deviation } \\
\hline & $x_{1}$ & $x_{2}$ & & & & \\
\hline & Moisture content $(w / v)$ & Bed loading (g) & & Observed & Predicted & \\
\hline 1 & -1 & -1 & 3.39 & 656.4 & 693.0 & 5.28 \\
\hline 2 & -1 & 0 & 3.57 & 823.1 & 743.7 & -10.68 \\
\hline 3 & -1 & 1 & 3.69 & 648 & 690.9 & 6.20 \\
\hline 4 & 0 & -1 & 3.34 & 1157.9 & 1129.8 & -2.49 \\
\hline 5 & 0 & 0 & 3.32 & 1004 & 1072.8 & 6.41 \\
\hline 6 & 0 & 1 & 3.54 & 953 & 912.3 & -4.46 \\
\hline 7 & 1 & -1 & 4.53 & 1818 & 1809.6 & -0.47 \\
\hline 8 & 1 & 0 & 4.29 & 1634.3 & 1644.9 & 0.65 \\
\hline 9 & 1 & 1 & 4.39 & 1379 & 1376.8 & -0.16 \\
\hline
\end{tabular}


test) measuring the correlation and the statistical significance of the model, respectively. With $R^{2}$ equal to 0.9879 , the model explains $98.79 \%$ of the total variation. Therefore, the mathematical model to describe xylanase activity can be represented by the following equation:

Xylanase activity $(\mathrm{U} / \mathrm{g} \mathrm{dcc})=1,072.8+450.6 \cdot x_{1}-108.7 \cdot x_{2}+121.5 \cdot x_{1}{ }^{2}-51.75 \cdot x_{2}{ }^{2}-107.65$. $x_{1} \cdot x_{2}$

Using this equation, the model predicted the values reported in Table 5. The relative deviations between observed and predicted values were lower than $11 \%$, indicating a close fit of the model to the experimental data. The predicted dependence of xylanase activity on $\mathrm{MC}$ and $\mathrm{BL}$ was drawn in Fig. 1a.

A significant effect of MC on xylanase production was observed (significant coefficient at the $99 \%$ confidence level), with values increasing from $656.4 \mathrm{U} / \mathrm{g}$ dcc under the lowest MC and $\mathrm{BL}$ to $1,818 \mathrm{U} / \mathrm{g}$ dcc at the highest moisture ratio and lowest BL. The influence of the initial MC of the substrate on the production of biomass-degrading enzymes by SSF has been widely described in the literature since the optimal value depends on both the solid substrate and the microorganism employed [23]. Thus, initial MC is a key factor considering that water is present in only limited amounts in SSF systems, having profound effects on the physicochemical properties of solids, and thus, when is available in lower or higher quantities than the optimum value affects the process productivity significantly [33]. For instance, it has been reported that a higher optimum moisture level causes different effect, including decreased porosity, alteration in particle structure, gummy texture, lower oxygen transfer, and enhancement of the formation of aerial mycelia, and even leads to conglomeration of the substrate or sticking of the particles to the wall of the reactor making the substrate more vulnerable to bacterial contamination [2, 6, 34]. Instead, lower MCs may be detrimental in several aspects reducing the solubility of nutrients in the solid substrate, lowering the degree of swelling capacity of substrate, decreased growth of microorganisms, and also lower enzyme production $[2,6,35]$. In our case, increasing moisture ratio clearly improved xylanase production, probably due to low water activities, insufficient for the development of the fungus when low MCs were evaluated.

The influence of BL was not so relevant in spite of the coefficient was significant at the 95 $\%$ confidence level. However, BL has been reported to be the most important factor affecting

Table 6 Coefficients, $t$ values, $p$ values, and significant coefficients for xylanase activity studying the influence of bed loading and mixture content using a $3 * *(2-0)$ full factorial design and statistical parameters $\left(R^{2}\right.$ and $\left.F\right)$ measuring the correlation and significance of the models

a) Coefficients, $t$ values, $p$ values, and significant coefficients

$\begin{array}{llllllll}\text { Factor } & \text { Coefficient } & \begin{array}{c}\text { Standard } \\ \text { error }\end{array} & \begin{array}{c}\text { Computed } \\ t \text { value }\end{array} & p \text { value } & \begin{array}{c}-95 \% \text { confidence } \\ \text { limits }\end{array} & \begin{array}{c}95 \% \text { confidence } \\ \text { limits }\end{array} & \begin{array}{c}\text { Significant } \\ \text { coefficients }\end{array} \\ b_{0} & 1,072.80 & 55.86 & 19.20 & 0.00 & 895.02 & 1,250.58 & 99.97 \\ b_{1} & 450.63 & 30.60 & 14.73 & 0.00 & 353.26 & 548.01 & 99.93 \\ b_{11} & 121.50 & 53.00 & 2.29 & 0.11 & -47.16 & 290.16 & 89.43 \\ b_{2} & -108.72 & 30.60 & -3.55 & 0.04 & -206.09 & -11.34 & 96.20 \\ b_{22} & -51.75 & 53.00 & -0.98 & 0.40 & -220.41 & 116.91 & 59.92 \\ b_{12} & -107.65 & 37.47 & -2.87 & 0.06 & -226.91 & 11.61 & 93.61 \\ \text { Statistical parameters } & & & & & & \text { Significance level } \\ \text { Variable } & R^{2} & \text { Corrected } R^{2} & & F_{\text {exp }} & >09.5 \%\end{array}$


other fermentative processes, such as the citric acid production by A. niger in an SSF process, because it influences the degree of aeration in the system [36]. BL can also be related to heat transfer, which is affected by higher restrictions in SSF than in submerged cultures, being therefore necessary to ensure the suited supply of oxygen and heat exchange to ensure an efficient growth of the microorganism [37].

Additionally, it was also observed that using a moisture ratio of 1:3.6, the $\mathrm{pH}$ increased to around 4.5, as Table 5 shows.

Finally, using the "solver" application of Microsoft Excel, the maximum xylanase activity predicted for the model $\left(y_{1}=1,809.6 \mathrm{U} / \mathrm{g} \mathrm{dcc}\right)$ was achieved when $x_{1}=1$ and $x_{2}=-1$,
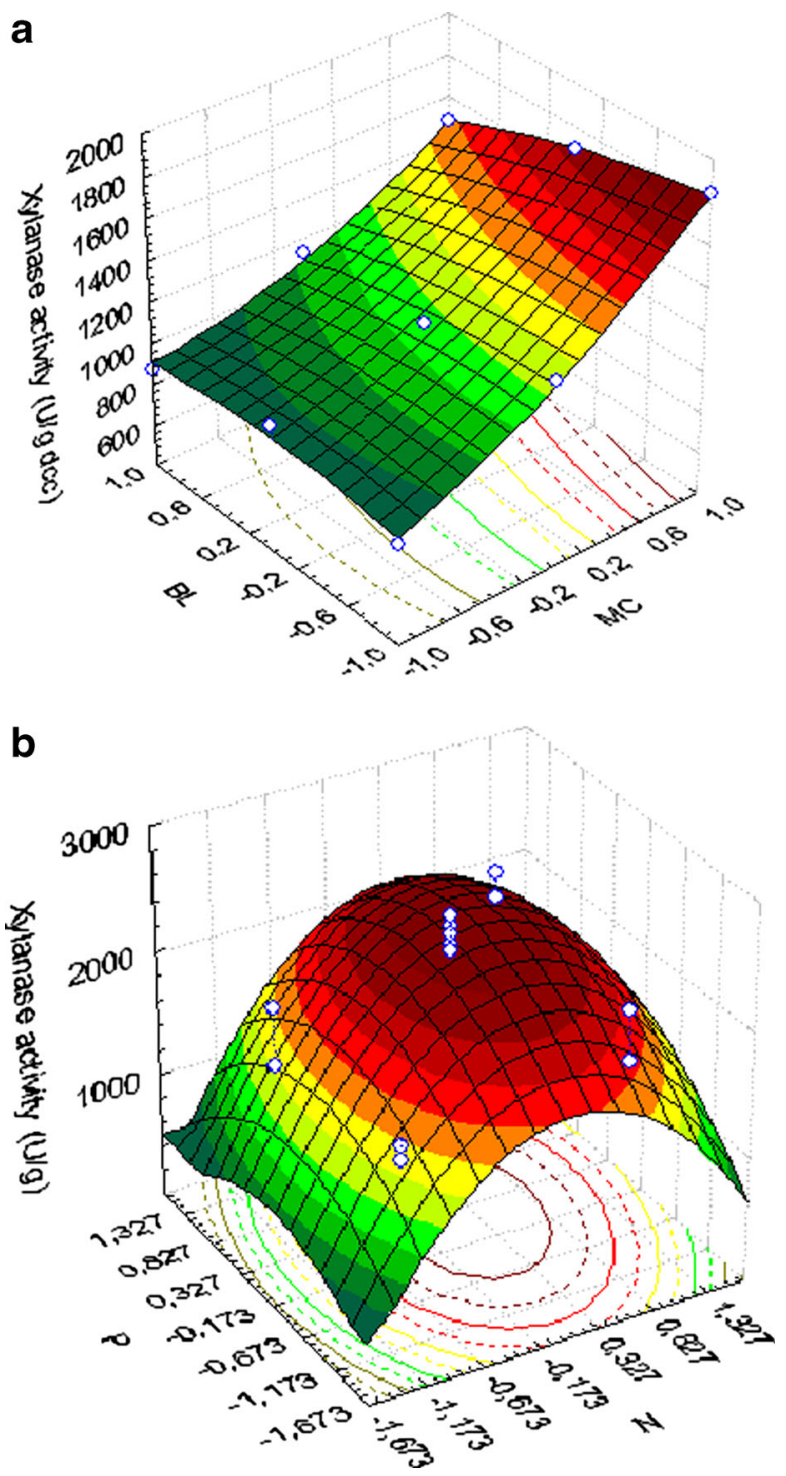

Fig. 1 Dependence of xylanase activity on a moisture content and bed loading according to a $3^{* *}(2-0)$ full factorial design and $\mathbf{b ~} \mathrm{N}$ and $\mathrm{P}$ concentrations following a $2^{3}$ rotatable central composite design 
corresponding to an $\mathrm{MC}$ of 1:3.6 (w/v) and a BL of $5 \mathrm{~g}$, respectively. These values were selected to carry out the second experimental design.

\section{Salt Concentration of Moistening Medium}

The influence of the mineral salt solution as moistening medium has been previously studied in SSF with contradictory results. For instance, Archana and Satyanarayana [2] evaluated tap water, distilled water, and a variety of salt solutions, finding that tap water supported xylanase production better than any mineral solution. However, Pal and Khaum [3] observed that the composition of the moistening media profoundly affected xylanase yield and mineral salt solutions and tap water resulted in higher xylanase production as compared to double-distilled water alone. The variety and amount of salts employed as moistening medium varied widely among authors [2, 4, 38-40]. Considering the variety of media studied and the diversity of results attained up to now, the use of an experimental design could enhance to a better understanding of the influence of the most common metal ions employed.

Table 7 compiles the coded independent variables considered (coded N, coded $\mathrm{P}$, and coded $\mathrm{Ca}$ ), the experimental data about xylanase activity, and the final $\mathrm{pH}$ value achieved in fermentation runs. The regression coefficients and the statistical significance of each coefficient based on the Student's $t$ test and probability $(p)$ values were summarized in Table 8; meanwhile, the goodness of the model was evaluated by the statistical parameters $\left(R^{2}, R^{2}\right.$ adjusted, $F$, and the significance level based on the $F$ test) measuring the correlation and the statistical significance of the model. The determination coefficient $\left(R^{2}=0.9630\right)$ indicated that $96.3 \%$ of the variability in the response can be explained by the model. It is usually accepted

Table 7 Central composite design (17 runs) for optimization of three variables (each on five levels) in mathematically predicted and experimental values for xylanase activity

\begin{tabular}{|c|c|c|c|c|c|c|c|}
\hline \multirow[t]{3}{*}{ Runs } & \multicolumn{3}{|c|}{ Coded level } & \multirow[t]{3}{*}{$\mathrm{pH}$} & \multicolumn{2}{|c|}{ Xylanase activity (U/g) } & \multirow[t]{3}{*}{ Relative deviation (\%) } \\
\hline & $x_{1}$ & $x_{2}$ & $x_{3}$ & & & & \\
\hline & $\mathrm{N}$ & $\mathrm{P}$ & $\mathrm{Ca}$ & & Observed & Predicted & \\
\hline 1 & -1 & -1 & -1 & 3.31 & 1,232 & $1,466.6$ & 16.0 \\
\hline 2 & -1 & 1 & 1 & 3.52 & 849 & $1,129.0$ & 24.8 \\
\hline 3 & 1 & -1 & 1 & 4.42 & 1,375 & $1,571.4$ & 12.5 \\
\hline 4 & 1 & 1 & -1 & 5.25 & 1,879 & $1,964.7$ & 4.4 \\
\hline 5 & -1 & -1 & 1 & 3.44 & 1,085 & $1,117.7$ & 2.9 \\
\hline 6 & -1 & 1 & -1 & 3.55 & 1,403 & $1,325.0$ & -5.9 \\
\hline 7 & 1 & -1 & -1 & 4.87 & 1,852 & $1,690.4$ & -9.6 \\
\hline 8 & 1 & 1 & 1 & 5.02 & 2,115 & $1,998.8$ & -5.8 \\
\hline 9 & -1.673 & 0 & 0 & 3.12 & 562 & 338.5 & -66.0 \\
\hline 10 & 1.673 & 0 & 0 & 3.49 & 1,199 & $1,253.4$ & 4.3 \\
\hline 11 & 0 & -1.673 & 0 & 4.61 & 1,660 & $1,536.4$ & -8.0 \\
\hline 12 & 0 & 1.673 & 0 & 4.93 & 1,821 & $1,775.5$ & -2.6 \\
\hline 13 & 0 & 0 & -1.673 & 4.72 & 2,429 & $2,437.7$ & 0.4 \\
\hline 14 & 0 & 0 & 1.673 & 4.95 & 2,352 & $2,174.2$ & -8.2 \\
\hline 15 & 0 & 0 & 0 & 4.87 & 2,245 & $2,327.9$ & 3.6 \\
\hline 16 & 0 & 0 & 0 & 4.93 & 2,182 & $2,327.9$ & 6.3 \\
\hline 17 & 0 & 0 & 0 & 4.69 & 2,523 & $2,327.9$ & -8.4 \\
\hline
\end{tabular}


Table 8 Coefficients, $t$ values, $p$ values, and significant coefficients for xylanase activity studding the influence of salt addition using a central composite design and statistical parameters $\left(R^{2}\right.$ and $F$ ) measuring the correlation and significance of the models

(a) Coefficients, $t$ values, $p$ values, and significant coefficients

\begin{tabular}{|c|c|c|c|c|c|c|c|}
\hline Factor & Coefficient & $\begin{array}{l}\text { Standard } \\
\text { error }\end{array}$ & $\begin{array}{l}\text { Computed } t \\
\text { value }\end{array}$ & $p$ value & $\begin{array}{l}-95 \% \text { confidence } \\
\text { limits }\end{array}$ & $\begin{array}{l}95 \% \text { confidence } \\
\text { limits }\end{array}$ & $\begin{array}{l}\text { Significant } \\
\text { coefficients }\end{array}$ \\
\hline $\mathrm{b}_{0}$ & $2,322.46$ & 98.85 & 23.49 & 0.00 & $2,088.71$ & $2,556.21$ & 99.99 \\
\hline$b_{1}$ & 275.92 & 46.55 & 5.93 & 0.00 & 165.85 & 386.00 & 99.94 \\
\hline $\mathrm{b}_{11}$ & -566.22 & 51.46 & -11.00 & 0.00 & -687.91 & -444.52 & 99.99 \\
\hline $\mathrm{b}_{2}$ & 78.78 & 46.55 & 1.69 & 0.13 & -31.30 & 188.86 & 86.56 \\
\hline$b_{22}$ & -223.36 & 51.46 & -4.34 & 0.00 & -345.05 & -101.67 & 99.66 \\
\hline $\mathrm{b}_{3}$ & -71.39 & 46.55 & -1.53 & 0.17 & -181.46 & 38.69 & 83.10 \\
\hline$b_{33}$ & 8.78 & 51.46 & 0.17 & 0.87 & -112.91 & 130.48 & 13.07 \\
\hline$b_{12}$ & 91.50 & 60.70 & 1.51 & 0.18 & -52.02 & 235.02 & 82.46 \\
\hline$b_{13}$ & 45.00 & 60.70 & 0.74 & 0.48 & -98.52 & 188.52 & 51.74 \\
\hline$b_{23}$ & 75.75 & 60.70 & 1.25 & 0.25 & -67.77 & 219.27 & 74.78 \\
\hline \multicolumn{8}{|c|}{ b) Statistical parameters } \\
\hline \multicolumn{2}{|c|}{ Variable } & $R^{2}$ & \multicolumn{2}{|l|}{ Corrected $R^{2}$} & $F_{\exp }$ & \multicolumn{2}{|c|}{$\begin{array}{l}\text { Significance level } \\
\quad \text { (based on the } F \text { test) }\end{array}$} \\
\hline \multicolumn{2}{|l|}{$y_{2}$} & 0.9630 & \multicolumn{2}{|l|}{0.9155} & 180.31 & \multicolumn{2}{|l|}{$99.5 \%$} \\
\hline
\end{tabular}

that a regression model with a determination coefficient higher than 0.9 is considered as having a very high correlation [41]; meanwhile, the value of the adjusted determination coefficient (adjusted $R^{2}=0.9155$ ) is also reasonably high, thus also indicating the goodness significance of the model. The model $F$ value of 180.31 also indicates that the model was significant. Finally, the model showed a significance level based on the $F$ test of $99.5 \%$.

In relation with the influence of the independent variables, nitrogen concentration $\left(x_{1}\right)$, followed by phosphorus concentration $\left(x_{2}\right)$, caused the strongest effects on the variation of the dependent variables considered, as it can be seen from the absolute value of the corresponding coefficients and considering that among individual coefficients, only coded nitrogen was significant at the $99 \%$ confidence level, and among quadratic terms, coded nitrogen and phosphorus were also significant at $99 \%$ confidence levels.

According to a multiple regression analysis among independent and dependent variables, the following quadratic model was proposed to explain the variation of xylanase activity as a function of the operational variables studied:

$$
\begin{aligned}
\text { Xylanase activity }(\mathrm{U} / \mathrm{g} \mathrm{dcc})= & 2,322.46+275.92 \cdot x_{1}+78.78 \cdot x_{2}-71.39 \cdot x_{3}-556.22 \cdot x_{1}{ }^{2}-223.36 \cdot x_{2}{ }^{2} \\
& +8.78 \cdot x_{3}{ }^{2}+91.50 \cdot x_{1} \cdot x_{2}+45.0 \cdot x_{1} \cdot x_{3}+75.75 \cdot x_{2} \cdot x_{3}
\end{aligned}
$$

Table 7 also summarizes the predicted values using this equation and the relative deviations; meanwhile, Fig. $1 \mathrm{~b}$ shows the predicted dependence of the xylanase activity $\left(y_{2}\right)$ on coded nitrogen $\left(x_{1}\right)$ and phosphorus $\left(x_{2}\right)$, at an intermediate level of calcium $\left(x_{3}=0\right)$. The strong positive effect of high nitrogen concentrations on xylanase activity was remarkable, which supports the convenience of adding nitrogen with the moistening medium previously reported by Pal and Khaum [3]. Similarly, the influence of phosphorus addition was also positive, although with a minor influence. The two negative second-order terms for $\mathrm{N}$ and $\mathrm{P}$ define the existence of a maximum 
value for xylanase activity at intermediate values so that higher values would lead to an excessive concentration which reduces the production of xylanases, probably as a cause of catabolic repression. In fact, higher xylanase activity $(2,437.7 \mathrm{U} / \mathrm{g} \mathrm{dcc})$ was predicted in experiment 13 under intermediate values of $\mathrm{N}\left(x_{1}=0\right)$ and $\mathrm{P}\left(x_{2}=0\right)$ and the lowest amount of $\mathrm{Ca}\left(x_{3}=-1.673\right)$. Using the solver application of Microsoft Excel, the maximum xylanase activity predicted for the model $(2,452.7 \mathrm{U} / \mathrm{g} \mathrm{dcc})$ was achieved when $x_{1}=0.17, x_{2}=0.05$, and $x_{3}=-1.673$, corresponding to $1.1 \mathrm{~g} / \mathrm{L}$ of nitrogen, $1.0 \mathrm{~g} / \mathrm{L}$ of phosphorus, and $0 \mathrm{~g} / \mathrm{L}$ of calcium, highlighting the convenience of not adding calcium to carry out these experiments.

Finally, similar to the study of $\mathrm{MC}$ and $\mathrm{BL}$, the $\mathrm{pH}$ was higher in flasks with higher xylanase production, showing the importance of keeping higher $\mathrm{pH}$ values (4-5).

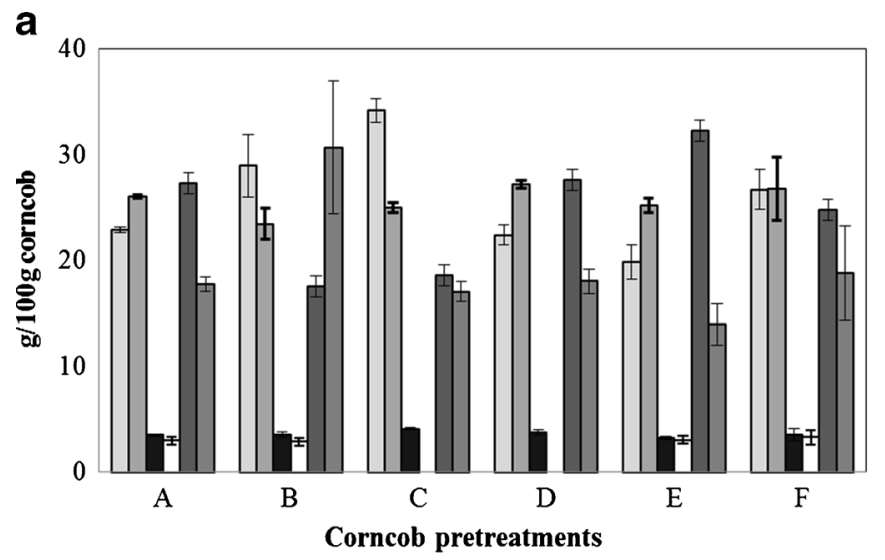

\section{$\square$ glucan $\square$ xilan $\square$ araban $\square$ acetil groups $\square$ Klason lignin $\square$ others}

b

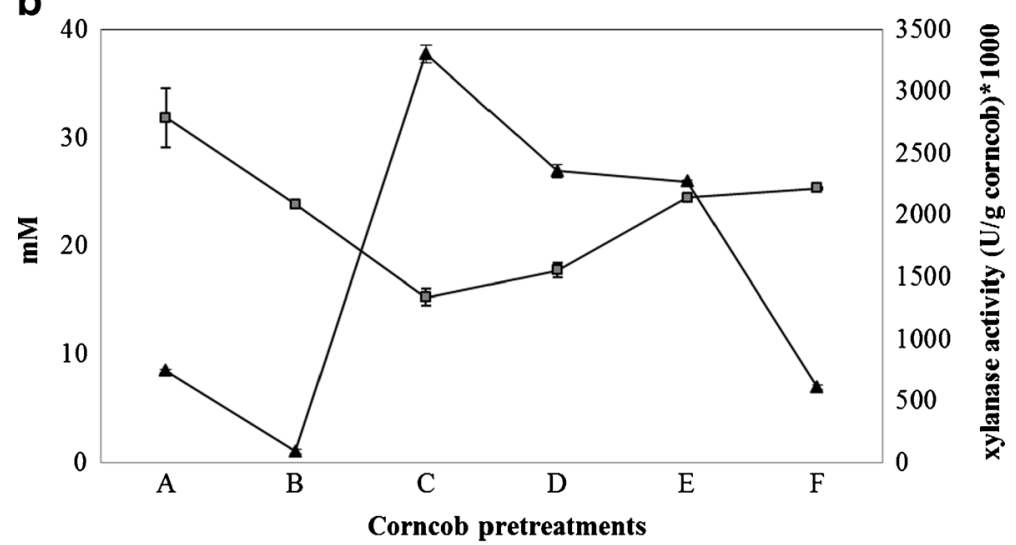

$\rightarrow$ oxalic acid (mM) $\quad \rightarrow$ xylanase activity $* 1000$ (U/g corn cob)

Fig. 2 a Composition (expressed in percentage oven-dry basis) of raw corncob $(A)$ and materials obtained after the following pretreatments: $(B)$ destarching, $(C)$ destarching followed by $\mathrm{NaOH}$ treatment, $(D)$ destarching followed by $\mathrm{NH}_{4} \mathrm{OH}$ treatment, $(E)$ destarching and autoclaving, and $(F)$ destarching followed by autoclaving and microwave. b Xylanase activities obtained after 8 days and oxalic acid achieved after 10 days. Results are expressed as the mean values of three replications and their standard deviations 

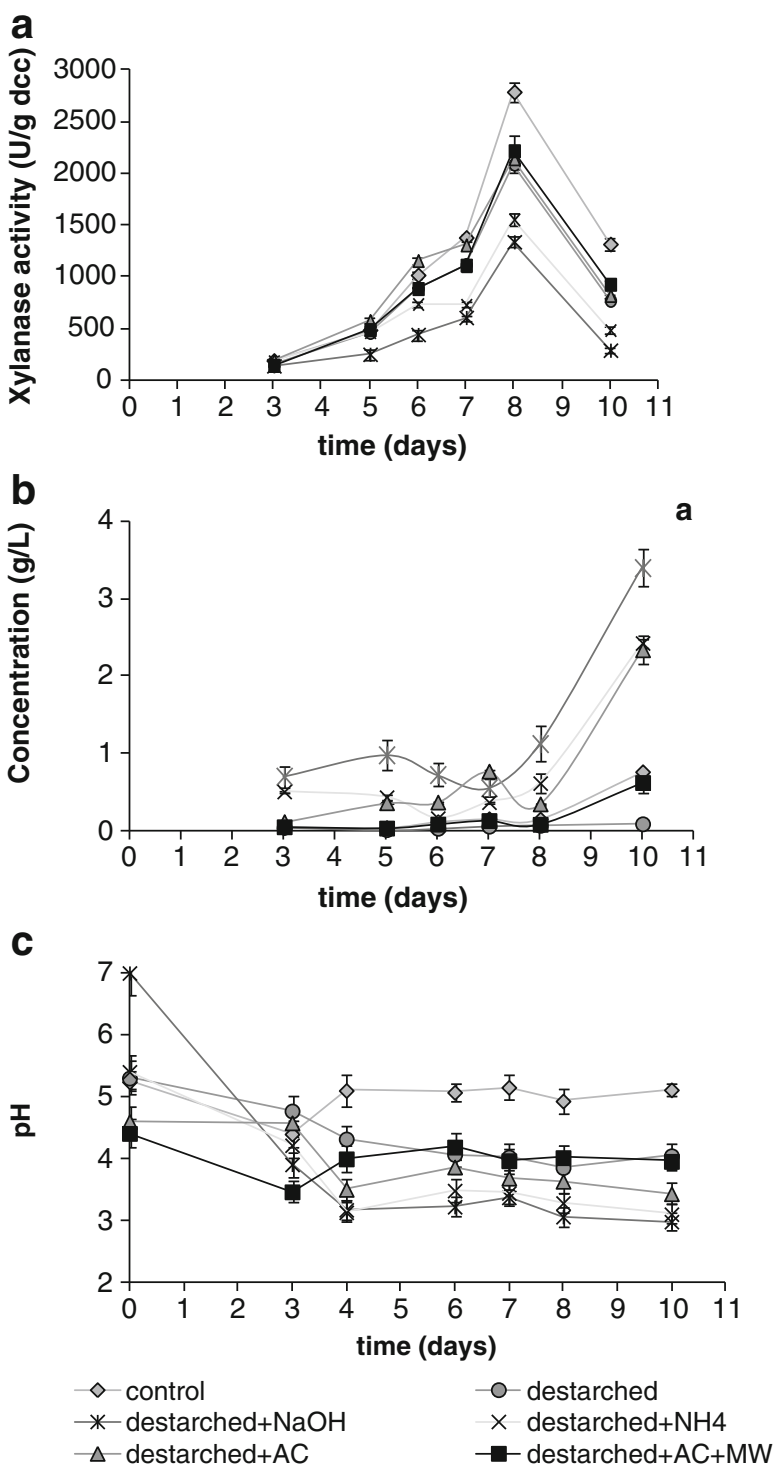

Fig. 3 Effect with time of pretreatments on a xylanase activity (in U/g dcc) obtained by Aspergillus niger CECT 2700 in an SSF process, $\mathbf{b}$ oxalic acid (in $\mathrm{g} / \mathrm{L}$ ), and $\mathbf{c} \mathrm{pH}$

Pretreatments of Material

A quantitative acid hydrolysis procedure was used to determine the composition of the raw material employed in this work using aliquots from the homogenized lot. Figure 2 shows the results indicating the mean values of three replications and their standard deviations (expressed in percentage oven-dry basis). The raw corncob was mainly composed of hemicelluloses, which account for $32.7 \%$ (including $22.9 \%$ xylan, $3.53 \%$ arabinan, and $3.0 \%$ acetyl groups), followed by Klason lignin with $27.4 \%$ and cellulose with $22.9 \%$. The filamentous fungus 

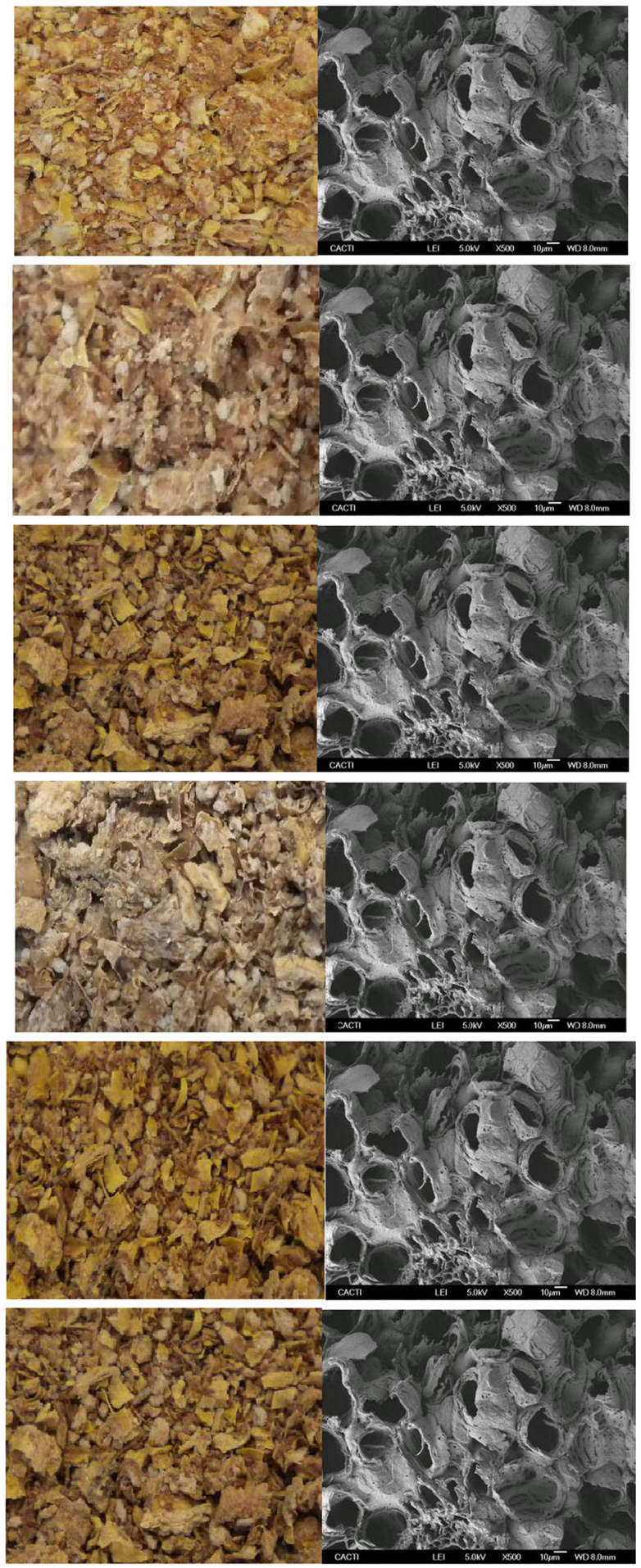
Fig. 4 Visual aspect and SEM photographs showing the morphology of lignocellulosic surface of a raw corncob, b destarched corncob, c destarched corncob followed by $\mathrm{NaOH}$ treatment, d destarched corncob followed by $\mathrm{NH}_{4} \mathrm{OH}$ treatment, e destarched corncob treated by autoclave, and $\mathbf{f}$ destarched corncob treated by autoclave and microwave

A. niger CECT 2700 showed capacity to produce extracellular xylanases in solid-state cultures made on raw corncob. The xylanolytic activity reached a maximal activity of 2,786.9 U/g dry corncob after 8 days (see Fig. 3a). However, this enzymatic activity decreased sharply in the following days, indicating that the endpoint of fermentation should be carefully controlled because synthesized xylanase could be degraded by nonspecific proteases secreted by the fungus [3].

Some authors have reported that the complexity of lignocellulosic materials, such as corn stover, leads to the stability of its biomass, thus resulting difficult to be enzymatically hydrolyzed [42]; consequently, some physical and chemical techniques have been reported to facilitate the stage of saccharification [43, 44]. Corncob contains some trace starch [45], which is a quickly consumable carbon source so it could lead to a repression in xylanase synthesis in certain organisms [25]. Thus, an enzymatic destarching step has also been reported as a preliminary pretreatment $[15,16]$, and consequently, it was applied to the corn cob as described in "Materials and Methods." Considering that substrates not only should provide nutrients for microorganisms but also allow oxygen transfer and heat dispersion [3], enzymatically destarched corncobs were submitted to alkaline pretreatments with $\mathrm{NaOH}$ or $\mathrm{NH}_{4} \mathrm{OH}$ or physic pretreatments with autoclave and microwave in order to evaluate their influence on the matrix structure and the fermentation.

In our case, the enzymatic destarching of the material decreased the xylanase activity to $2,086.7 \mathrm{U} / \mathrm{g}$ dcc. It could be related to the lower xylan content of the destarched material with regard to glucan as a consequence of the partial solubilization and loss of hemicelluloses during the boiling treatment. But, what is quite interesting is the different effect of the pretreatments applied on the morphology of the matrix as it can be observed by FE-SEM in Fig. 4. The structure of corncobs seemed to be unchanged after enzymatic destarching (B), meaning that this stage mainly affects the release of starch but not changing substantially its structure regarding to the raw material (A).

The observations also revealed that alkali pretreatments could break down the structural rigidity of the lignocellulosic matrices, as a consequence of the delignification stage, making some micropores inside (C, D). Lignin content was reduced from $27.4 \%$ in the control to 18.6 $\%$ after destarching and $\mathrm{NaOH}$ treatments, although the treatment with ammonium hydroxide did not alter the composition $(27.7 \%)$. The formation of micropores should represent a considerable increment of the surface area and, consequently, in the accessibility of the enzymes inside the microfibrils. However, lignocellulose material pretreatments could also cause a collapse in pore structure, resulting in a decrease of enzymatic hydrolyzability [44]. In our case, the production of xylanases under SSF of corncob decreased under all cases studied, to 1551.5 and $1334.8 \mathrm{U} / \mathrm{g}$ dcc using $\mathrm{NH}_{4} \mathrm{OH}$ - and $\mathrm{NaOH}$-pretreated corncob, respectively. This could be due to alkaline pretreatments that have removed completely the acetyl groups (see Fig. 2), which are responsible for xylan solubility in water [46]; consequently, the availability of xylan quantified in Fig. 2 could be severely reduced. Zhu et al. [47] and Rahnama et al. [48] have also reported similar findings. As a consequence, the complexity of the untreated substrate could impact and induce greater enzyme production [25, 48, 49].

The visual aspects and SEM images compiled in Fig. 4 (E and F) after the thermal processes showed that the structure of the materials was apparently not affected after the processing. Too severe thermal pretreatment conditions promote the condensation and 
precipitation of soluble lignin compounds, and there is a risk of formation of phenolic and heterocyclic compounds which can be inhibitory [44]. The autoclaved pretreated corncob allowed the production of $2,139.5 \mathrm{U} / \mathrm{g}$ dcc of xylanases, which was similar to the results obtained with the destarched material, thus showing that this thermal treatment has no negative effect on enzyme production, but neither a favorable influence.

Most of common biomass pretreatments that require high temperatures use conductive heating from an external heat source, and long reaction times are required, thus showing disadvantages like high-energy consumption and generation of inhibitory or toxic products in side reactions [50]. Oppositely to conventional thermal processes, efficient internal heating produced by microwave irradiation allows a spectacular heating acceleration, being recently explored as a potential lignocellulosic pretreatment [43, 50]. Taherzadeh and Karimi [51] suggested that microwave irradiation degrades primary cellulose and xylan, resulting in available free sugars for microorganisms. Xylanase activity produced by $A$. niger CECT 2700 using destarched corncob treated by autoclave and microwave reached 2,216.8 U/g dcc, meaning that both physic pretreatments allowed our strain to produce high xylanase activity enzymes similar to those obtained using destarched or destarched autoclaved corncob as carbon source.

The aforementioned results showed that additional pretreatments to destarched corncobs did not improve considerably xylanase production, giving in all cases values lower to those obtained using raw material. Rahnama et al. [48] and Shah and Madamwar [52] also found their best results for xylanase production using untreated corncob as substrate. Furthermore, it has to be considered that microwave or autoclave pretreatments implicate higher energy consumption and additional costs and are less environmentally friendly. All these inconveniences have made untreated corncob as the best alternative for xylanolytic enzyme production by $A$. niger CECT 2700 .

Additionally, in order to know whether this strain produced other metabolites, the culture extracts were also analyzed by HPLC. Among organic acids, a steadily increase in oxalic acid was observed with time to reach a maximum concentration of $8.5 \mathrm{mM}$ after 10 days of fermentation (Fig. 3b). Oxalic acid, a useful chemical in various hydrometallurgical processes, is mainly produced by $A$. niger depending on medium $\mathrm{pH}$ [53] Additionally, this fungus secretes other carboxylic acids (mainly citric or gluconic acids) depending on the carbon source and fermentative conditions [54]. Although it has been reported that glucose is more

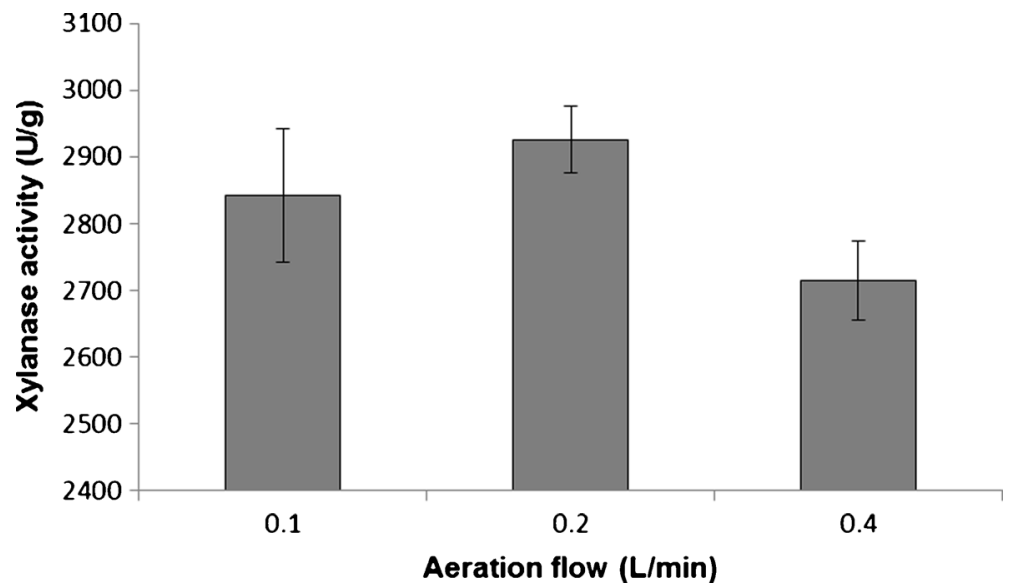

Fig. 5 Xylanase activity in a horizontal tube reactor, as a function of aeration rate 
easily converted to gluconic acid in submerged cultures, fungus immobilization seems to promote oxalic acid production [53]. In our case, other organic acids were also detected but in negligible amounts; particularly, malic acid was quantified after 8 days of fermentation in concentrations of $0.28 \mathrm{mM}$.

\section{Xylanase Production in Horizontal Tube Bioreactor}

Maximization of the rate of formation and yield of product within the bioreactor is a key part of optimizing the production process, especially considering that SSF bioreactor systems are yet to reach a high degree of development, in contrast to $\mathrm{SmF}$ systems, mainly due to the problems associated with solid beds like poor mixing and heat transfer characteristics and material handling [1]. Final experiments were conducted with raw corncob using a horizontal tube bioreactor, since this position allowed maximizing the surface exposed to airflow, thus increasing the poor results achieved in a vertical position (data not shown). The aeration and oxygen transfer were handled passing different airflow rates through the fermentation system. The results achieved (see Fig. 5) indicated that aeration rate presented significant effect $(p<0.05)$ on xylanase activity, achieving the highest result $(2,926 \mathrm{U} / \mathrm{g}$ dry corncobs $)$ at a flow rate of $0.2 \mathrm{~L} / \mathrm{min}$. These results were higher than those obtained in previous experiments using Erlenmeyer flaks, where the model to study the influence of salts predicted a maximum xylanase activity of 2,452.7 and 2,786.9 U/g dec during the pretreatment of materials. Additionally, these values were higher than those in recent reports, including the work of Pal and Khanum [3] that produced up to 2,596 IU of xylanases/g dry substrate, from A. niger DFR-5 through SSF using a mixture of wheat bran and soybean cake.

\section{Other Enzymes}

Although this article was focused on xylanase production, other enzymes (cellulases, cellobiases, and feruloyl esterases) were produced in lower amounts. Table 9 summarizes this information in different steps, expressed in $\mathrm{U} / \mathrm{g} \mathrm{dcc}$, showing the evolution observed for xylanase activity. Cellulase is another enzyme with industrial interest. Cellulase produced by fungi usually contains three components: $\beta$-1,4-endoglucanase, $\beta$-1,4-exoglucanase, and cellobiase ( $\beta$-glucosidase) [55]. The hydrolysis of natural cellulose to glucose depends on the synergism of these three enzymes. $\beta$-Glucosidase, the enzyme responsible for the hydrolysis of cellobiose to glucose, has received much attention primarily because the efficiency of this step is critical to the overall breakdown of cellulose [56]. On the other hand, feruloyl esterase is an inducible enzyme capable of hydrolyzing the ester bonds between sugars (the arabinose side chain in the case of corncob xylan) and the monomeric or dimeric ferulates present in plant cell [57]. A. niger, different Penicillium sp., and the thermophilic fungus

Table 9 Enzyme activities before and after optimization

\begin{tabular}{lllll}
\hline \multicolumn{4}{c}{ Enzymes activity } \\
\cline { 2 - 5 } & Xylanase (U/g) & Cellulase (U/g) & Cellobiase (U/g) & Feruloyl esterase (U/g) \\
\hline First fermentation & 552 & 0.7056 & 2.9252 & 0.5538 \\
$\begin{array}{l}\text { Optimization in flasks } \\
\text { Fermentation in column reactor } \\
\quad(0.2-\mathrm{L} / \text { min aeration) }\end{array}$ & 2,553 & 0.957 & 2.5986 & 0.3834 \\
\hline
\end{tabular}


Sporotrichum thermophile were capable of producing this enzyme when they were grown on agricultural residues such as sugar beet pulp, wheat bran, wheat straw, and brewer's spent grain under SSF [58]. Despite the improvement of the xylanase production with the optimization and scale-up, cellulase, cellobiase, and feruloyl esterase activities almost changed in the different conditions assayed. In any case, these activities were residual in comparison to xylanase, so that the extracts obtained after solid-state culture of $A$. niger CECT 2700 on raw corncob can be considered xylanase extracts.

Acknowledgments We are grateful to the Spanish Ministry of Science and Innovation for the financial support of this work (project CTQ2011-28967), which has partial financial support from the FEDER funds of the European Union; to the Leonardo da Vinci Programme for founding the stay of Felisbela Oliveira in Vigo University; to MAEC-AECID (Spanish Government) for the financial support for Pérez-Bibbins, B. and to Spanish Ministry of Education, Culture and Sports for Pérez-Rodríguez's FPU; and to Solla E. and Méndez J. (CACTI-University of Vigo) for their excellent technical assistance in microscopy.

\section{References}

1. Raghavarao, K. S., Ramganathan, T. V., \& Karanth, N. G. (2003). Biochemical Engineering Journal, 13, 127-135.

2. Archana, A., \& Satyanarayana, T. (1997). Enzyme and Microbial Technology, 21, 12-17.

3. Pal, A., \& Khanum, F. (2010). Bioresource Technology, 101, 7563-7569.

4. Badhan, A. K., Chadha, B. S., Kaur, J., Saini, H. S., \& Bhat, M. K. (2007). Bioresource Technology, 98,504 510 .

5. Kulkarni, N., Shendye, A., \& Rao, M. (1999). FEMS Microbiology Reviews, 23, 411-456.

6. Chapla, D., Divecha, J., Madamwar, D., \& Shah, A. (2010). Biochemical Engineering Journal, 49, 361-369.

7. Bakri, Y., Al-Jazairi, M., \& Al-Kayat, G. (2008). Polish Journal of Microbiology, 57(3), 249-251.

8. Lakshmi, G. S., Rao, C. S., Rao, R. S., Hobbs, P. J., \& Prakasham, R. S. (2009). Biochemical Engineering Journal, 48, 51-57.

9. Qureshi, N., \& Blaschek, H. P. (2000). Transactions Institute of Chemical Engineers, 78((Part C), $139-144$.

10. Food and Agriculture Organization of the United Nations. FAOSTAT. Available in: http://faostat.fao.org. Accessed September 26, 2013.

11. Senthilkumar, S. R., Ashokkumar, B., Raj, K. C., \& Gunasekaran, P. (2005). Bioresource Technology, 96(12), 1380-1386.

12. Wong, K. K. Y., Tan, L. U. L., \& Saddler, J. N. (1988). Microbiological Reviews, 52, 305-317.

13. Prade, R. A. (1996). Biotechnology and Genetic Engineering Reviews, 13, 120-131.

14. Maciel, G. M., Vandenberghe, L. P. S., Haminiuk, C. W. I., Fendrich, R. C., Bianca, B. E. D., Brandalize, T. Q. S., Pandey, A., \& Soccol, C. R. (2008). Food Tech. Biotech, 46(2), 183-189.

15. Saulnier, L., Marot, C., Elgorriaga, M., Bonnin, E., \& Thibault, J. F. (2001). Carbohydrate Polymers, 45, 269-275.

16. Bonnin, E., Saulnier, L., Brunel, M., Marot, C., Lesage-Meessen, L., Asther, M., \& Thibault, J. F. (2002). Enzyme and Microbial Technology, 31, 1000-1005.

17. Pang, F., Xue, S., Yu, S., Zhang, C., Li, B., \& Kang, Y. (2013). Industrial Crops Products, 42, $402-408$.

18. Vázquez, D., Lage, M. A., Parajó, J. C., \& Vázquez, G. (1991). Revista Agroquimica Tecnologia, 31, 143164.

19. Miller, L. (1959). Analytical Chemistry, 31, 426-428.

20. Bailey, M. J., Biely, P., \& Poutanen, K. (1992). J of Biotechnology, 23, 257-270.

21. Ghose, T. K. (1987). Pure and Applied Chemistry, 59, 257-268.

22. Mastihuba, V., Kremnický, L., Mastihubová, M., Willett, J. L., \& Côté, G. L. (2002). Analytical Biochemistry, 309, 96-101.

23. Delabona, P. D. S., Pirota, R. D. P. B., Codima, C. A., Tremacoldi, C. R., Rodrigues, A., \& Farinas, C. S. (2013). Industrial Crops and Products, 42, 236-242.

24. Hang, Y. D., \& Woodams, E. E. (2001). LWT Food Science and Technology, 34(7), $484-486$. 
25. Haltrich, D., Nidetzky, B., Kulbe, K. D., Steiner, W., \& Župančič, S. (1996). Bioresource Technology, 58, $137-161$.

26. Haapala, R., Linko, S., Parkkinen, E., \& Sumominen, P. (1994). Biotechnology Techniques, 8, 401-406.

27. Salgado, J. M., Rodríguez, N., Cortés, S., \& Domínguez, J. M. (2009). Journal of Agricultural and Food Chemistry, 57, 10414-10428.

28. Salgado, J. M., Martínez Carballo, E., Max, B., \& Domínguez, J. M. (2010). Bioresource Technology, 101, 2379-2388.

29. Benedetti, A. C. E. P., da Costa, E. D., Aragon, C. C., dos Santos, A. F., Goulart, A. J., Attili-Angelis, D., \& Monti, R. (2013). Revista de Ciencias Farmaceuticas Basica Aplicada, 34(1), 25-31.

30. Rao, R. S., Kumar, C. G., Prakasham, R. S., \& Hobbs, P. J. (2008). Biotechnology Journal, 3, 510-523.

31. Téllez-Luis, S. J., Moldes, A. B., Alonso, J. L., \& Vázquez, M. (2003). Journal of Food Science, 68(4), $1454-1458$.

32. de Lima, C. J. B., Coelho, L. F., da Silva, G. P., Alvarez, G. L. M., \& Contiero, J. (2010). Journal of Microbial and Biochemical Technology, 2(3), 64-69.

33. Lonsane, B. K., Saucedo-Castaneda, G., Raimbault, M., Roussos, S., Viniegra-Gonzalez, G., Ghildyal, N. P., Ramakrishna, M., \& Krishnaiah, M. M. (1992). Process Biochemistry, 27, 259-273.

34. Shah, A. R., \& Madamwar, D. (2005). World Journal of Microbiology Biotechnology, 21, 233-243.

35. Poorna, C. A., \& Prema, P. (2007). Bioresource Technology, 98, 485-490.

36. Lu, M., Brooks, J. D., \& Maddox, I. S. (1997). Enzyme and Microbial Technology, 21(6), 392-397.

37. Torrado, A. M., Cortés, S., Salgado, J. M., Max, B., Rodríguez, N., Bibbins, B. P., Converti, A., \& Domínguez, J. M. (2011). Brazilian Journal of Microbiology, 42, 394- 409.

38. Camassola, M., \& Dillon, A. J. P. (2007). Journal of Applied Microbiology, 103(6), 2196-2204.

39. Nair, S. G., Sindhu, R., \& Shashidhar, A. (2008). African J. Microbiological Research, 2, 82-86.

40. Seyis, I., \& Aksoz, N. (2005). Food Tech. Biotech, 43(1), 37-40.

41. Rao, Y. K., Lu, S. C., Liu, B. L., \& Tzeng, Y. M. (2006). Biochemical Engineering Journal, 28, 57-66.

42. Lin, Z., Huang, H., Zhang, H., Zhang, L., Yan, L., \& Chen, J. (2010). Applied Biochemistry and Biotechnology, 162, 1872-1880.

43. Alvira, P., Tomás-Pejó, E., Ballesteros, M., \& Negro, M. J. (2010). Bioresource Technology, 101, 4851-4861.

44. Hendriks, A. T. W. M., \& Zeeman, G. (2009). Bioresource Technology, 100, 10-18.

45. Wang, Z., Keshwani, D. R., Redding, A. P., \& Cheng, J. J. (2010). Bioresource Technology, 101, 3583-3585.

46. Van Dyk, J. S., \& Pletschke, B. I. (2012). Biotechnology Advances, 30, 1458-1480.

47. Zhu, S., Wu, Y., Yu, Z., Liao, J., \& Zhang, Y. (2005). Process Biochemistry, 40(9), 3082-3086.

48. Rahnama, N., Mamat, S., Shah, U. K. M., Ling, F. H., Rahman, N. A. A., \& Ariff, A. B. (2013). BioResources, 8(2), 2881-2896.

49. Mosier, N., Wyman, C., Dale, B., Elander, R., Lee, Y. Y., Holtzapple, M., \& Ladisch, M. (2005). Bioresource Technology, 96, 673-686.

50. Monteil-Rivera, F., Huang, G. H., Paquet, L., Deschamps, S., Beaulieu, C., \& Hawari, J. (2012). Bioresource Technology, 104, 775-782.

51. Taherzadeh, M. J., \& Karimi, K. (2008). International Journal of Molecular Sciences, 9, 1621-1651.

52. Shah, A. R., \& Madamwar, D. (2005). World J. Microbial Biotechnology, 21, 233-243.

53. Mandal, S. K., \& Banerjee, P. C. (2005). Process Biochemistry, 40, 1605-1610.

54. Mattey, M. (1992). CRC Critical Reviews in Biotechnology, 12, 87-132.

55. Shen, X., \& Xia, L. (2004). Process Biochemistry, 39, 1363-1367.

56. Yeoh, H. H., Tan, T. K., Chua, S. L., \& Lim, G. (1998). MIRCEN J, 4, 425-430.

57. Shin, H. D., \& Chen, R. R. (2006). Enzyme and Microbial Technology, 38, 478-485.

58. Fazary, A. E., \& Ju, Y. H. (2007). Acta Biochimica et Biophysica Sinica, 39, 811-828. 